\title{
Controlling the laxative abuse of anorexia nervosa patients with the Serigaya Methamphetamine Relapse Prevention Program workbook: a case report
}

\author{
Kuniyoshi Toyoshima ${ }^{1,2^{*}}$ and Ichiro Kusumi ${ }^{2}$
}

\begin{abstract}
Background: There is no consensus on effective treatment for laxative abuse in patients with eating disorders. Here, we report the case of a patient with laxative abuse who showed some improvement through an intervention based on the Matrix model.

Case presentation: A woman diagnosed with anorexia nervosa-binge eating/purging type (AN-BP) steadfastly denied laxative abuse and would not admit to suffering from an eating disorder. This led to low motivation for undergoing conventional psychotherapy, psychoeducation, and cognitive behavioral therapy. These were ineffective and followed by repeated cycles of hospitalization and discharge. The patient's general condition, as depicted by her laboratory and clinical parameters, deteriorated due to the medical complications resulting from laxative abuse.

Focusing on laxative abuse, we considered an intervention for drug addiction. Because the patient could maintain a diet diary and acknowledged laxative abuse as a drug addiction, we introduced the Serigaya Methamphetamine Relapse Prevention Program (SMARPP) workbook as a self-administered treatment. The patient meticulously completed the treatment and experienced a gradual improvement in laxative abuse. She has not been rehospitalized in 4 years, currently performs household chores, and demonstrates improved social function.
\end{abstract}

Conclusions: In patients with AN-BP, the SMARPP workbook may be effective in treating laxative abuse.

Keywords: Addiction, Anorexia nervosa-binge eating/purging type, Laxative abuse, Matrix model, SMARPP workbook

\section{Background}

Anorexia Nervosa (AN) constitutes a debilitating and often fatal eating disorder, wherein the restraint of appetite and emotion occurs simultaneously with an obsessive-compulsive behavior in addition to a cognitive disposition that demonstrates significant attention to detail [1]. The compulsivity of AN has sometimes raised the notion that the condition may embed some degree of addictive behavior [2]. In AN patients with low body weight, their physiological systems are affected, resulting in conditions ranging from hypotension and osteopenia

\footnotetext{
* Correspondence: toyoshima@med.hokudai.ac.jp

${ }^{1}$ Department of Psychiatry, Wakkanai City Hospital, Wakkanai, Japan

${ }^{2}$ Department of Psychiatry, Graduate School of Medicine, Hokkaido

University, Kita 15, Nishi 7, Sapporo 060-8638, Japan
}

to life-threatening arrhythmias. The electrolyte anomalies that occur in patients with purging or frequent laxative abuse often necessitates rapid treatment [3]. Reportedly, family-based treatment is effective for adolescent patients with AN [4]. This may be due to the shorter duration of illness that adolescent patients experience in comparison to adult patients as well as their tendency to live around family members who can provide moral and emotional support that may disincentivize their use of laxatives. However, the efficacy of this approach remains unclear for middle-aged patients [5].

Recent evidence-based therapeutic advances for adult patients with AN include cognitive remediation therapy, exposure therapy, and non-invasive neuromodulation [6]. Although psychotherapy, in addition to cognitive

(c) The Author(s). 2019 Open Access This article is distributed under the terms of the Creative Commons Attribution 4.0 International License (http://creativecommons.org/licenses/by/4.0/), which permits unrestricted use, distribution, and reproduction in any medium, provided you give appropriate credit to the original author(s) and the source, provide a link to the Creative Commons license, and indicate if changes were made. The Creative Commons Public Domain Dedication waiver (http://creativecommons.org/publicdomain/zero/1.0/) applies to the data made available in this article, unless otherwise stated. 
behavioral therapy, is the fundamental treatment for $\mathrm{AN}$, it has not been proven effective in several cases. In fact, patients with purging AN who exhibit both vomiting and laxative abuse manifested the poorest course [7]. This is part of the underlying reason for the proposal that purging behavior should be comprehensively evaluated in patients with eating disorders because it is usually not self-reported due to the associated shame [8].

Against this background, this paper reports the case of a woman with anorexia nervosa-binge eating/purging type (AN-BP), whose state of physical crisis deteriorated due to laxative abuse and led to her recurrent hospitalization. Adopting a drug addiction perspective, we attempted an intervention for laxative abuse using the Serigaya Methamphetamine Relapse Prevention Program (SMARPP) workbook. This is a form of cognitive behavioral therapy that correlates the features of an eating disorder with drug cravings and harm to both the brain and body. On this basis, we evaluated the efficacy of the SMARPP workbook for the aforementioned patient.

\section{Case presentation}

A 49-year-old woman with anorexia nervosa-binge eating/purging type (AN-BP) and a simultaneous history of laxative abuse was admitted to our hospital for the second time. According to her medical history, she had initiated dieting after entering vocational school at the age of 18. Initially, she practiced only dietary restrictions but gradually began self-induced vomiting. Based on the medical history she provided, her weight $(50 \mathrm{~kg})$ decreased gradually and was $40 \mathrm{~kg}$ by the time she got married at 28. During this time, she had begun consuming a commercially available laxative. By age 35 , her body weight was $35 \mathrm{~kg}$. She was diagnosed with impaired renal function at 41 and renal failure occurred at 45; subsequently, hemodialysis was initiated. At this time, she was diagnosed with $\mathrm{AN}$ on a visit to a nearby mental clinic, but refused hospitalization.

Throughout this period, the patient continued to restrict her diet and abuse laxatives. At the age of 46, her body weight decreased to $<30 \mathrm{~kg}$, and dialysis became difficult because of the decrease in her blood pressure. She was advised to undergo hospitalization at a specialized medical institution, and in October of the same year, she was admitted to our facility. Her weight was $26.4 \mathrm{~kg}$ [body mass index (BMI), $11.9 \mathrm{~kg} / \mathrm{m}^{2}$ ], and we confirmed her fear of obesity, body image distortion, and purging behavior, which included self-induced vomiting and laxative abuse. No questionnaire or semi-structured interview was employed to confirm an eating disorder. Rather, the patient was diagnosed with AN-BP using the fourth edition of the Diagnostic and Statistical Manual of Psychiatric Disorders (DSM-IV-TR) [9]. At the onset of her eating disorder, the patient exhibited binge eating and had begun vomiting via laxative use to compensate for her overconsumption.

\section{Clinical assessments}

Table 1 presents the values obtained via our clinical assessments. Cognitive behavioral therapy was administered to the patient using a column technique and nutritional therapy. Her weight increased to $38 \mathrm{~kg}$ in May at the age of 47, and she was discharged in August. As soon as she was discharged, she relapsed and resumed laxative abuse. The patient visited our hospital once a week, but her body weight gradually decreased to the 20-kg range. She was re-hospitalized in February at the age of 49. Upon admission, her weight was $33.7 \mathrm{~kg}$ (BMI, $15.2 \mathrm{~kg} / \mathrm{m}^{2}$ ). Based on the following laboratory indices, serum creatinine $(4.43 \mathrm{mg} / \mathrm{dl} \uparrow)$, serum sodium (Na $137 \mathrm{mEq} / \mathrm{l} \downarrow)$, serum potassium $(3.0 \mathrm{mEq} / \mathrm{l} \downarrow)$ serum chlorine $(102 \mathrm{mEq} / \mathrm{l})$, and blood urea nitrogen $(22 \mathrm{mg} /$ $\mathrm{dl}$ ); an internal medicine specialist made a diagnosis of pre-renal renal failure due to laxative abuse. This led to her placement under maintenance hemodialysis. In addition to systemic management using central venous nutrition, behavioral therapy was also administered, and her body weight gradually increased $(+5.3 \mathrm{~kg} / 3$ months) By May, her body weight was $39 \mathrm{~kg}$ (BMI, $17.6 \mathrm{~kg} / \mathrm{m}^{2}$ ) after dialysis. The patient was eating a $1600 \mathrm{KCal}$ meal at this time; however, she expressed fear of obesity, body image distortion, and a desire to remain slim. Also, while we found no fecal storage in the X-ray performed each week, she insisted on using a laxative. As such, we surmised that while her original intent for abusing laxatives was to reduce weight, her intention had evolved such that her use of laxatives had become a top priority to eliminate anxiety. This prompted us to adopt a drug addiction intervention.

\section{Clinical management via SMARPP workbook}

We introduced the SMARPP workbook and used it to conceptualize laxative abuse as an addiction. We chose this approach because at the heart of the phenomenon of addiction is the erosion of the desire to refrain from harmful behavior, which is caused by neuroplastic changes in the brain that limit the rational control of such harmful behavior [10]. A clinical examination of the attitude of a patient with AN toward laxative abuse in light of DSM supported our approach. We think this approach is preferable to the use of CBT, which conceptualizes the laxative abuse of AN as only a purging behavior.

SMARPP is based on cognitive behavioral therapy and includes topics on the correlation of an eating disorder with drug cravings and harm to the brain and body. It comprises weekly group sessions, including motivational interviewing attitudes [11] and cognitive behavioral therapy for relapse prevention, following the Matrix model 
Table 1 Clinical Assessments

\begin{tabular}{llll}
\hline & $\begin{array}{l}\text { Before SMARPP } \\
\text { (May, at the age of 49) }\end{array}$ & $\begin{array}{l}\text { After SMARPP } \\
\text { (December, at the age of 49) }\end{array}$ & $\begin{array}{l}\text { Follow-up } \\
\text { (January, at 53 years) }\end{array}$ \\
\hline GAF scale & 35 & 50 & 65 \\
Body weight & $39 \mathrm{~kg}$ & $45.5 \mathrm{~kg}$ & $41.0 \mathrm{~kg}$ \\
BMI & $17.6 \mathrm{~kg} / \mathrm{m}^{2}$ & $20.5 \mathrm{~kg} / \mathrm{m}^{2}$ & $18.5 \mathrm{~kg} / \mathrm{m}^{2}$ \\
SCOFF-Sick & no & no & no \\
SCOFF-Control & yes & no & no \\
SCOFF-One-stone (14 lbs./6.5 kg) & no & no & no \\
SCOFF-Fat & yes & no & no \\
SCOFF-Food & yes & no & no \\
\hline
\end{tabular}

Abbreviations: GAF global assessment of functioning, BMI body mass index, SCOFF sick, control, one stone, fat, and food

[12]. The SMARPP workbook utilizes the SMARPP principles. The Japanese version was published in 2011 as the "Recovery Support Workbook from Drug-Alcohol Addiction." It comprises 28 chapters, which both patients and psychiatrists can read and complete together while adjusting to the patients' pace. Each chapter required approximately $30 \mathrm{~min}$ for completion and the patient read the chapter for the first $15 \mathrm{~min}$ and answered questions during the next $15 \mathrm{~min}$. Upon completion of each chapter, we evaluated the patient's impressions. The whole exercise was performed once a week for 7 months in our hospital environment.

During this period, the patient herself recognized her laxative abuse and admitted to having previously used approximately 30 tablets each night; she also confessed to using approximately 200 tablets. In fact, from August (at the age of 47) to February (at the age of 49), her laxative abuse gradually increased from 30 tablets to 200 tablets per day. The laxatives she used were commercially available (Bisacodyl; $5 \mathrm{mg}$, and Sennoside A B; $5.27 \mathrm{mg}$, per tablet). In December, at the age of 49 , she completed the table on the recurrence and reuse cycle in the last session (Fig. 1). In addition, at the conclusion of the SMARPP workbook, she stated, "I thought there was so much damage to my brain and my body." Nonetheless, her weight continued to increase further, and she was discharged in December at the age of 49 years, once her body weight reached $45.5 \mathrm{~kg}$ (BMI, $20.5 \mathrm{~kg} / \mathrm{m}^{2}$ ) after dialysis. We examined the effectiveness of the SMARPP workbook as shown in Fig. 2. The SMARPP workbook intervened in the laxative abuse, which resulted in appropriate laxative use and reduced compulsive and impulsive behaviors.

In the cognitive functional battery conducted upon her discharge, the results of the Continuous Performance Test errors improved compared with that performed before her discharge. The Continuous Performance Test (CPT) was applied using a stimulus presentation software $(\mathrm{A}-\mathrm{X} \mathrm{CPT})$ and lasted for $7 \mathrm{~min}$. This test assesses

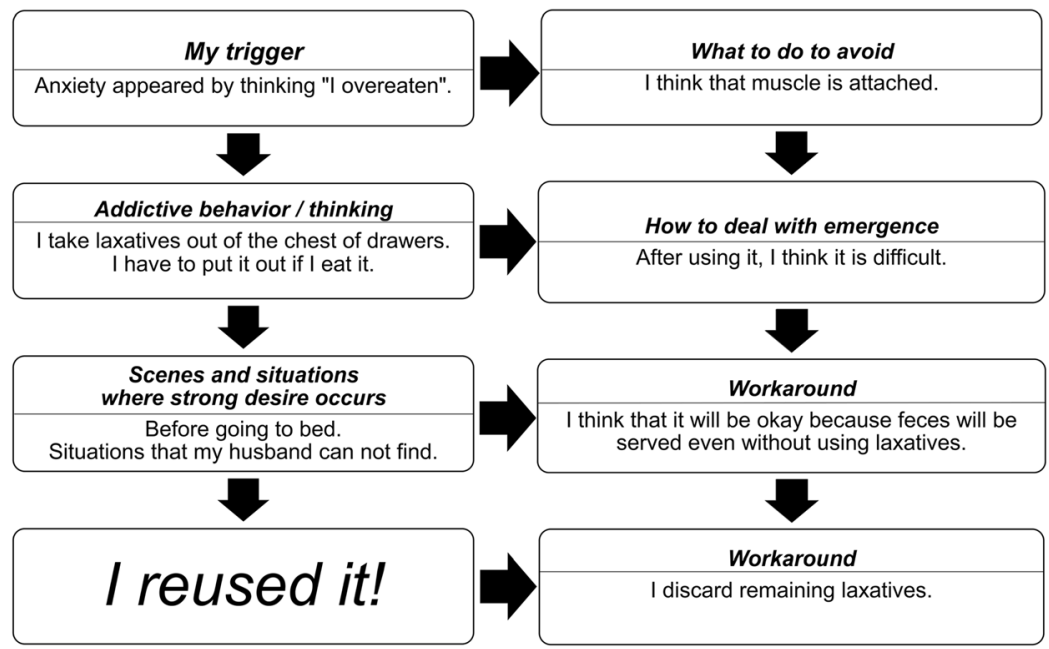

Fig. 1 SMARPP workbook. (The patient reviewed the cycle of recurrence, reuse, and ways to manage her disease) 


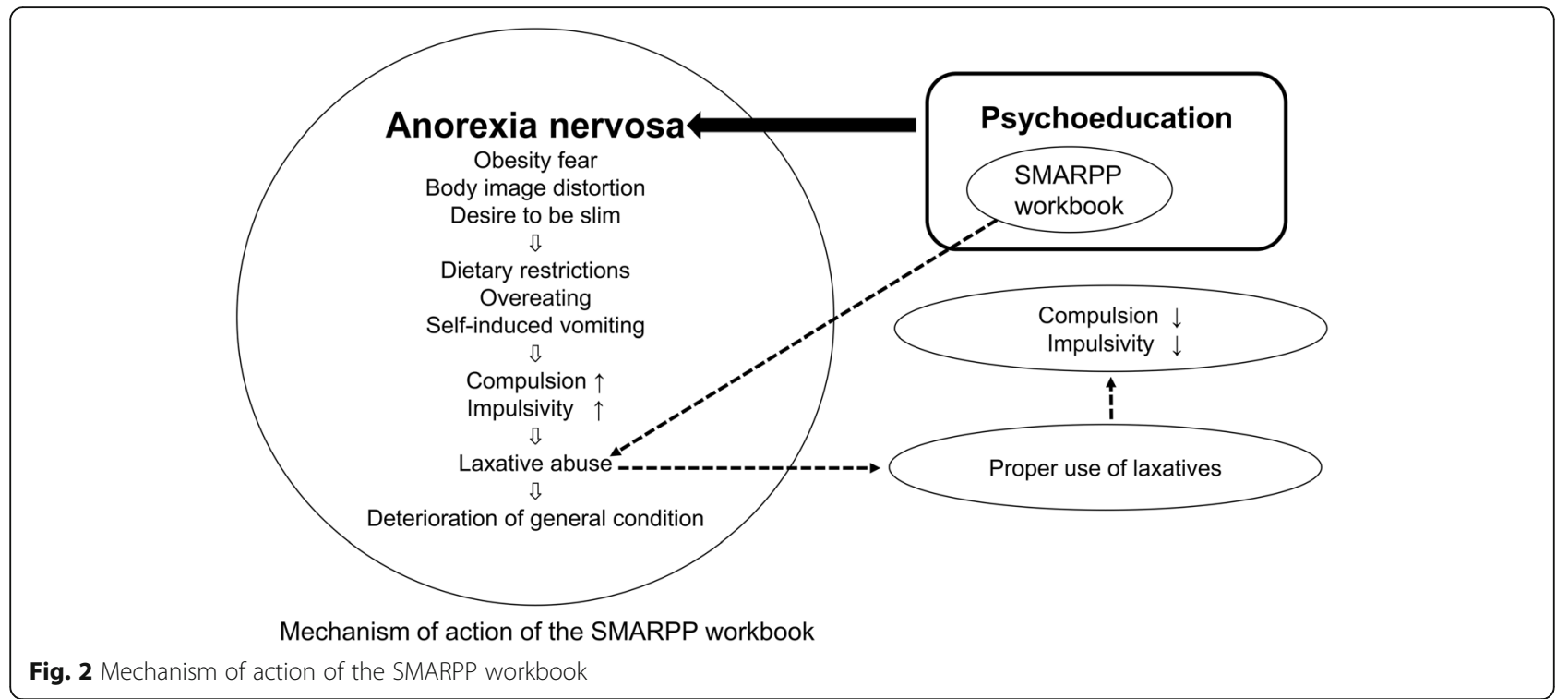

the participant's sustained attention and reaction time [13]. Post-discharge, she continued outpatient visits until March, when she reached the age of 53; she has not been re-hospitalized since. The prescription content of her laxative was Sennoside A B, $48 \mathrm{mg}$; Sennoside A, B, $2 \mathrm{~g}$; Lubiprostone, $48 \mu \mathrm{g}$; and Sodium Picosulfate Hydrate, $15 \mathrm{mg}$ per day, whereas at the time of laxative abuse, it was Bisacodyl, $1000 \mathrm{mg}$ and Sennoside A B, $1054 \mathrm{mg}$ per day.

From Table 2, it can be seen that overall there were improvements in the blood pressure (from hypotension to normotension) and BMI of our patient with reference to her initial hospitalization, second hospitalization, and her conditions at discharge and follow-up. Though still elevated, her creatinine level was on a decline compared to her first hospitalization. Also, whereas her hemoglobin and albumin levels were still low, they were better at discharge $(10.6 \mathrm{~g} / \mathrm{L}$ and $3.2 \mathrm{~g} / \mathrm{L}$ respectively) compared to when she was first hospitalized $(6.2 \mathrm{~g} / \mathrm{L}$ and $2.6 \mathrm{~g} / \mathrm{L}$ respectively).

Before the SMARPP workbook was adopted, the patient underreported the amount of laxative she used. However, once the workbook was implemented, she provided the correct laxative dose. She also admitted her laxative abuse to medical staff and family members. From that point, she began to work independently to prevent the recurrence of laxative abuse. Figure 3 presents the contents of the SMARPP workbook. In addition, her progress following the adoption of the workbook showed that her weight gain and food intake were stable. This is depicted in Fig. 4.

\section{Discussion and conclusions}

It has been observed that AN with a bingeing component increases a patient's vulnerability to a substance use disorder [1]. Seen against this background, the present case is significant, as it provides an empirical perspective on laxative abuse in the context of AN-BP. This reinforces the idea that a behavioral and neurobiological correlation exists between AN and addiction [14]. However, it is still a novel concept because the laxative abuse of patients with eating disorders is generally not considered a form of addiction $[15,16]$.

In this case, we found that the patient's laxative abuse improved when the SMARPP workbook was used as a therapeutic tool. Because the patient's serum potassium concentration normalized following the amelioration of laxative abuse, we excluded other differential diagnoses, such as renal tubular acidosis, which may be seen in autoimmune conditions, including Sjögren's syndrome or hereditary renal tubular disorders [17, 18]. In the treatment of eating disorders, a referral for psychiatric treatment may sometimes help decrease the patient's reliance on laxatives [15]. Although a correlation exists between laxatives and anxiety in bulimia nervosa (BN) [19], laxative misusers with AN tend to abuse laxatives more than those with BN [20]. However, compared to the number of reports on the effective treatment of laxative abuse for $\mathrm{BN}$, few reports focus on an effective treatment for laxative abuse for those with AN [3].

Due to the effect of the associated low body weight, AN has a lower cognitive component compared to BN [21]. This suggests that a complicated psychological intervention for AN patients with low body weight is difficult. The SMARPP workbook appears quite easy to use and as such may be started from the low weight spectrum of AN. As noted earlier, laxative abuse by older adults may require more external intervention compared to adolescent abusers, who are likely to have others nearby who can provide moral and emotional support; thus, we believe that it may be better to 
Table 2 Laboratory \& Clinical Findings

\begin{tabular}{|c|c|c|c|c|}
\hline & Initial hospitalization & Re-hospitalization & At discharge & $\begin{array}{l}\text { Follow-up } \\
\text { (May, at the age of } 52 \text { years) }\end{array}$ \\
\hline Height $(\mathrm{cm})$ & 149 & 149 & 149 & 149 \\
\hline Weight (kg) & 26.4 & 33.7 & 45.4 & 42.0 \\
\hline $\mathrm{BMI}\left(\mathrm{kg} / \mathrm{m}^{2}\right)$ & 11.9 & 15.2 & 20.4 & 18.9 \\
\hline Physical findings & Remarkable emaciation & $\begin{array}{l}\text { Marked } \\
\text { Edema in both lower thighs }\end{array}$ & No noteworthy findings & No noteworthy findings \\
\hline Chest X-ray & CTR 25\% & CTR $42.7 \%$ & CTR $49.4 \%$ & CTR $47.2 \%$ \\
\hline Body temperature $\left({ }^{\circ} \mathrm{C}\right)$ & 35.7 & 36.9 & 36.4 & n.a \\
\hline Blood pressure & $79 / 49$ & $66 / 36$ & $107 / 63$ & n.a \\
\hline Pulse rate (times/min adjustment) & 92 & 84 & 98 & n.a \\
\hline \multicolumn{5}{|l|}{ Blood tests [reference values] } \\
\hline $\mathrm{RBC}\left(\times 10^{6} / \mu \mathrm{l}\right)[3.86-4.92]$ & $1.97 \downarrow$ & $2.55 \downarrow$ & $3.44 \downarrow$ & $3.39 \downarrow$ \\
\hline $\mathrm{Hb}(\mathrm{g} / \mathrm{dl})$ [11.6-14.8] & $6.2 \downarrow$ & $8.2 \downarrow$ & $10.6 \downarrow$ & $10.1 \downarrow$ \\
\hline TP $(g / d l)[6.6-8.1]$ & $4.2 \downarrow$ & $4.7 \downarrow$ & $5.7 \downarrow$ & $6.1 \downarrow$ \\
\hline Alb (g/dl) [4.1-5.1] & $2.6 \downarrow$ & $1.7 \downarrow$ & $3.2 \downarrow$ & $3.1 \downarrow$ \\
\hline BUN (mg/dl) [8-20] & 10 & $22 \uparrow$ & $48 \uparrow$ & 15 \\
\hline Cre (mg/dl) [0.46-0.79] & $5.72 \uparrow$ & $4.43 \uparrow$ & $7.25 \uparrow$ & $3.51 \uparrow$ \\
\hline $\mathrm{Na}(\mathrm{mEq} / \mathrm{l})$ [138-145] & $130 \downarrow$ & $137 \downarrow$ & 139 & 140 \\
\hline $\mathrm{K}(\mathrm{mEq} / \mathrm{l})[3.6-4.8]$ & $2.5 \downarrow$ & $3.0 \downarrow$ & 4.1 & 4.0 \\
\hline $\mathrm{Cl}(\mathrm{mEq} / \mathrm{l})$ [101-108] & $98 \downarrow$ & 102 & 105 & 105 \\
\hline $\mathrm{Ca}(\mathrm{mg} / \mathrm{dl})[8.8-10.1]$ & $8.4 \downarrow$ & 9.2 & 8.8 & 9.2 \\
\hline fT3 $(\mathrm{pg} / \mathrm{ml})[2.1-3.8]$ & $1.55 \downarrow$ & $1.49 \downarrow$ & n.a. & n.a. \\
\hline fT4 (ng/ml) [0.82-1.63] & 1.06 & $0.41 \downarrow$ & n.a. & 1.35 \\
\hline TSH ( $\mu \mathrm{lU} / \mathrm{ml})[0.38-4.31]$ & $10.02 \uparrow$ & 2.71 & n.a. & $11.20 \uparrow$ \\
\hline
\end{tabular}

n.a Not available

\begin{tabular}{|c|c|}
\hline 1. Why should I stop drinking alcohol and drugs? & 15. For recovery (2) - Social reintegration and associates \\
\hline 2. Trigger and desire (1) & 16. Impact of stimulant on body and brain \\
\hline 3. Trigger and desire (2) & 17. What is addiction? \\
\hline 4. Mental disorders and alcohol / substance abuse & 18. Detect dangerous situations \\
\hline 5. Let's separate from alcohol and drugs that are familiar & 19. Three pillars to quit alcohol - About anti-alcohol \\
\hline 6. Recovery stage from alcohol / drug living - the first year & 20. How to prevent recurrence \\
\hline 7. Things to watch out for living without alcohol and drugs & 21. Prognosis of people with alcohol problems \\
\hline 8. Let's make a schedule for the life of the future & 22. Justification for recurrence \\
\hline 9. Alcohol as a legal drug & 23. Disability of the body by alcohol (1) - Illness of the liver - \\
\hline 10. Marijuana is safer than tobacco? & 24. Problems of sex and how to spend your holiday \\
\hline 11. Triggering $\rightarrow$ thinking $\rightarrow$ desire $\rightarrow$ use & 25. Disability of the body by alcohol (2) - Diseases of other organs - \\
\hline 12. About the trigger around you & 26. Be wiser than becoming stronger \\
\hline 13. About the trigger in you & 27. Dysfunction of alcohol, brain, nerve, muscle \\
\hline 14. For recovery (1) - Trust and honesty & 28. What cycle is your recurrence / reuse? \\
\hline
\end{tabular}




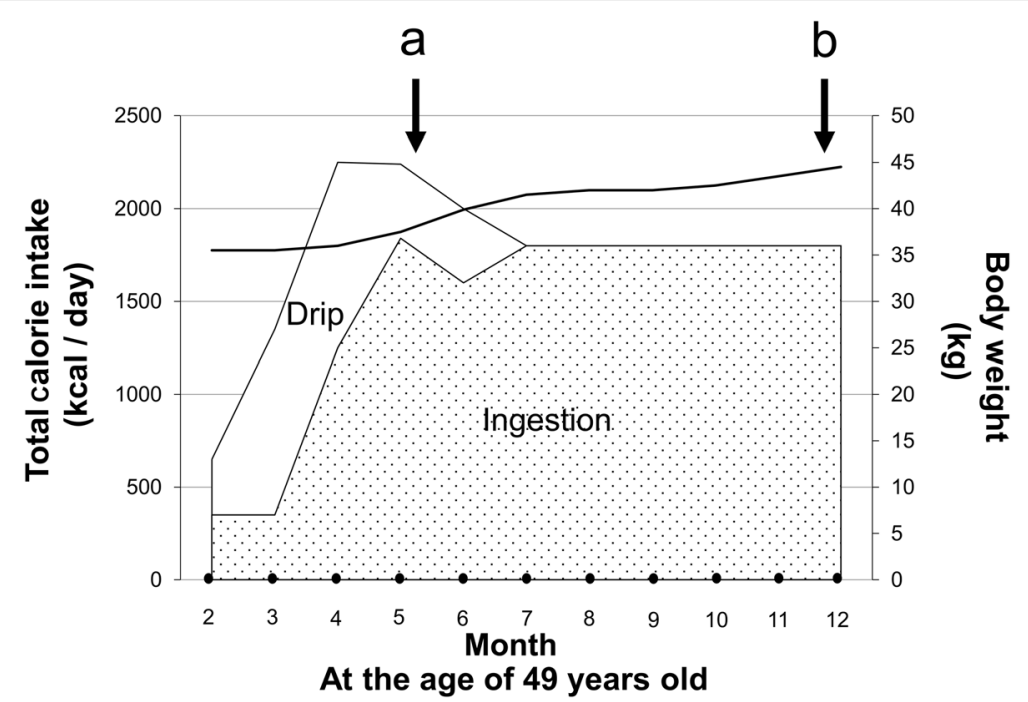

Fig. 4 Progress chart following hospitalization. The patient's progress following the adoption of the SMARPP workbook showed that her weight gain and food intake were stable. Abbreviations: a, SMARPP workbook started; b, SMARPP workbook finished

formulate interventions for laxative abuse by middleaged patients from a drug-dependence perspective.

The combination of self-induced vomiting and laxative-diuretic abuse is more typical in males than in females [22]. The presentation of female AN patients with these symptoms may therefore suggest the need for a thorough clinical history as well as the possibility of employing an addiction intervention strategy, such as SMARPP. However, because this is a case report, this idea cannot be generalized. Nevertheless, the acknowledgment of laxative abuse as a drug addiction in the present case led to the patient's motivation for treatment, which resulted in an excellent prognosis. Because aberrant cognitions related to eating and shape alter the functioning of central reward systems and reward processing, particularly in the context of illness-compatible cues, these may be exploited to develop treatment and preventive approaches to AN [23] and suggest the clinical value of the SMARPP workbook. This may also explain why the SMARPP workbook has been identified as a convenient tool for increasing patients' awareness and motivation in the treatment of drug addiction [24]. It remains to be seen whether the recently reported webbased relapse prevention program "e-SMARPP" will exert this same effect [25].

Despite the fact that laxative abuse in AN-BP sufferers is a clinically serious problem, no effective evidence-based treatment has been established. This case report reveals that using the SMARPP workbook for the treatment of drug dependence could be effective in treating laxative abuse in patients with AN-BP (Table 2 and Fig. 4). We assert that if the duration of the illness is long, a dependence on laxatives has been formed or the patient's cognitive function is declining; hence, the SMARPP workbook may be effective. Nevertheless, future study of similar cases to assess the efficacy of the SMARPP workbook on a larger scale is necessary. Whereas this may be the first report in which the SMARPP workbook is used to treat an eating disorder, and it is imperative to study more cases before generalizable conclusions can be drawn for its use in patients with AN-BP.

In this case, the evidence of recovery from eating disorder pathology was limited because SCOFF is usually used for screening of eating disorders. However, the psychopathology of eating disorder cannot be measured by this tool. In future studies, further objective assessment should be performed to confirm whether the SMARPP workbook contributes to the improvement of eating disorder pathology.

\section{Abbreviations}

AN: Anorexia nervosa; AN-BP: Anorexia nervosa-binge eating/purging type; BMI: Body mass index; BN: Bulimia nervosa; SMARPP: Serigaya Methamphetamine Relapse Prevention Program

\section{Acknowledgements}

We would like to thank Dr. Nobuki Kitagawa, Kouichi Ito, Yuki Kako, and their colleagues in the Psychopathology Clinical Conference and Hokkaido University for their collegial support, as well as our colleagues at Wakkanai City Hospital for their clinical support.

\section{Authors' contributions}

$\mathrm{KT}$ wrote the case report and the initial draft of the manuscript. IK assisted in the preparation of the manuscript. All authors contributed to data collection and interpretation and critically reviewed the manuscript. All authors approved the final version of the manuscript,and agree to be accountable for all aspects of the work in ensuring that questions related to the accuracy or integrity of any part of the work are appropriately investigated and resolved. 


\section{Funding}

This research did not receive any specific grant from funding agencies in the public, commercial, or non-profit sectors.

\section{Availability of data and materials}

Data sharing is not applicable to this article as no datasets were generated or analyzed during the current study.

\section{Ethics approval and consent to participate}

The study was approved by the Local Ethics Committee of Wakkanai City Hospital (Ethics Approval Number: H30-3). Informed consent was obtained from the patient.

\section{Consent for publication}

We obtained consent for publication from the patient herself.

\section{Competing interests}

The authors declare that they have no competing interests.

Received: 7 December 2018 Accepted: 2 October 2019

Published online: 23 October 2019

\section{References}

1. Brooks SJ. A debate on working memory and cognitive control: can we learn about the treatment of substance use disorders from the neural correlates of anorexia nervosa? BMC Psychiatry. 2016;16:10.

2. Godier LR, Park RJ. Does compulsive behavior in anorexia nervosa resemble an addiction? A qualitative investigation. Frontiers Psychol. 2015;6:1608.

3. Harrington $B C$, Jimerson M, Haxton C, Jimerson DC. Initial evaluation, diagnosis, and treatment of anorexia nervosa and bulimia nervosa. Am Fam Physician. 2015;91:46-52.

4. Couturier J, Kimber M, Szatmari P. Efficacy of family-based treatment for adolescents with eating disorders: a systematic review and meta-analysis. Int J Eat Disord. 2013;46:3-11.

5. Neubauer K, Weigel A, Daubmann A, Wendt H, Rossi M, Löwe B, et al. Paths to first treatment and duration of untreated illness in anorexia nervosa: are there differences according to age of onset? Europ Eat Disord Rev. 2014;22: 292-8.

6. Brockmeyer T, Friederich $\mathrm{HC}$, Schmidt U. Advances in the treatment of anorexia nervosa: a review of established and emerging interventions. Psychol Med. 2018;48:1228-56.

7. Støving RK, Andries A, Brixen KT, Bilenberg N, Lichtenstein MB, Hørder K. Purging behavior in anorexia nervosa and eating disorder not otherwise specified: a retrospective cohort study. Psychiatry Res. 2012;198:253-8.

8. Keifenheim KE, Giel KE, Leehr EJ, Becker S, Moerike K, Zipfel S, et al. Difficulties in addressing purging behavior in the treatment of a patient with anorexia nervosa. Dtsch Med Wochenschr. 2013;138:1670.

9. American Psychiatric Association. Diagnostic and statistical manual of psychiatric disorders. 4th ed. Washington DC: American Psychiatric Association; 2000.

10. Afolabi MOS, Sodeke SO. Reconciling competence and consent in opioiddependence research: the value of vulnerability rhetoric. Am J Bioeth. 2017; 17:48-50.

11. Matsumoto T. A treatment for drug dependence not requiring specialists: a treatment program based on a workbook, the "SMARPP.". Seishin Shinkeigaku Zasshi. 2015;117:655-62.

12. Obert JL, McCann MJ, Marinelli-Casey P, Weiner A, Minsky S, Brethen P, et al. The matrix model of outpatient stimulant abuse treatment: history and description. J Psychoactive Drugs. 2000;32:157-64.

13. Toyoshima K, Fujii Y, Mitsui N, Kako Y, Asakura S, Martinez-Aran A, et al. Validity and reliability of the cognitive complaints in bipolar disorder rating assessment (COBRA) in Japanese patients with bipolar disorder. Psychiatry Res. 2017;254:85-9.

14. Godier LR, Park RJ. Compulsivity in anorexia nervosa: a transdiagnostic concept. Front Psychol. 2014;5:778.

15. Roerig JL, Steffen KJ, Mitchell JE, Zunker C. Laxative abuse: epidemiology, diagnosis and management. Drugs. 2010;70:1487-503.

16. Sato $Y$, Fukudo $S$. Gastrointestinal symptoms and disorders in patients with eating disorders. Clin J Gastroenterol. 2015;8:255-63.
17. Mohee K, Kucharska-Pietura K, Karthigeyan A, Al N. Diagnostic and treatment dilemmas of persistent chronic hypokalaemia in a patient with anorexia nervosa: a case report. J Med Case Rep. 2014;8:294.

18. NICE Clinical Guidelines, No. 9. Eating Disorders: Core Interventions in the Treatment and Management of Anorexia Nervosa, Bulimia Nervosa and Related Eating Disorders: National Collaborating Centre for Mental Health. London: British Psychological Society; 2004.

19. Weltzin TE, Bulik CM, McConaha CW, Kaye WH. Laxative withdrawal and anxiety in bulimia nervosa. Int J Eat Disord. 1995;17:141-6.

20. Elran-Barak R, Goldschmidt AB, Crow SJ, Peterson CB, Hill L, Crosby RD, et al. Is laxative misuse associated with binge eating? Examination of laxative misuse among individuals seeking treatment for eating disorders. Int J Eat Disord. 2017:50:1114-8.

21. Zakzanis KK, Campbell Z, Polsinelli A. Quantitative evidence for distinct cognitive impairment in anorexia nervosa and bulimia nervosa. J Neuropsychol. 2010;4:89-106.

22. Valente S, Di Girolamo G, Forlani M, Biondini A, Scudellari P, De Ronchi D, et al. Sex-specific issues in eating disorders: a clinical and psychopathological investigation. Eat Weight Disord. 2017;22:707-15.

23. O'Hara CB, Campbell IC, Schmidt U. A reward-centred model of anorexia nervosa: a focussed narrative review of the neurological and psychophysiological literature. Neurosci Biobehav Rev. 2015;52:131-52.

24. Matsuoto T, Chiba Y, Imamura F, Kobayashi O, Wada K. Possible effectiveness of intervention using a self-teaching workbook in adolescent drug abusers detained in a juvenile classification home. Psychiatry Clin Neurosci. 2011;65:576-83.

25. Takano A, Miyamoto Y, Kawakami N, Matsumoto T, Shinozaki T, Sugimoto T. Web-based cognitive behavioral relapse prevention program with tailored feedback for people with methamphetamine and other drug use problems: protocol for a multicenter randomized controlled trial in Japan. BMC Psychiatry. 2016;16:87.

\section{Publisher's Note}

Springer Nature remains neutral with regard to jurisdictional claims in published maps and institutional affiliations.

Ready to submit your research? Choose BMC and benefit from

- fast, convenient online submission

- thorough peer review by experienced researchers in your field

- rapid publication on acceptance

- support for research data, including large and complex data types

- gold Open Access which fosters wider collaboration and increased citations

- maximum visibility for your research: over $100 \mathrm{M}$ website views per year

At BMC, research is always in progress.

Learn more biomedcentral.com/submissions 